\begin{tabular}{|c|c|c|c|}
\hline & $\begin{array}{l}\text { FATIH } \\
\text { SULTAN } \\
\text { MEHMET } \\
\text { VAKIF ÜNivERSiTESi }\end{array}$ & $\begin{array}{l}\text { FSM İlmî Araştırmalar Insan ve Toplum Bilimleri Dergisi } \\
\text { FSM Scholarly Studies Journal of Humanities and Social Sciences } \\
\text { Sayı/Number } 18 \text { Yıl/Year } 2021 \text { Güz/Autumn } \\
\text { C } 2021 \text { Fatih Sultan Mehmet Vakıf Üniversitesi }\end{array}$ & aris \\
\hline DOI: & & http://dergipark.org.tr/fsmia & http://dergi.fsm.edu.tr \\
\hline Araştır & lesi / Research Article & Geliş Tarihi / Received: 29.04.2021 Kabul Tarihi / Accepted: 04.06.2021 & FSMIAD, 2021; (18): 317-334 \\
\hline
\end{tabular}

\title{
Bağlanma ve Duyarlılık Davranışlarının 3-5 Yaş Çocukları Üzerinden Nesiller Arası Aktarımla İncelenmesi
}

\author{
Zeynep Deniz Seven* \\ Serdal Seven ${ }^{* *}$ \\ Feyza Uçar Çabuk ${ }^{* * \star}$
}

\section{$\ddot{O} \mathbf{z}$}

$\mathrm{Bu}$ araştırmanın amacı, bağlanma ve duyarlılık davranışlarının nesiller arası aktarımla 3-5 yaş çocukları üzerinden yansımasını incelemektir. Araştırma karma desenlidir. Araştırmaya 2 anneanne ve bunların 3-5 yaş aralığında çocuğu olan birisi ikincil bağlanmaya sahip ikişer kızları dahil edilmiştir. Böylece 3 nesilden toplam 10 kişi araştırmaya katılmıştır. Bağlanma durumları Yakın İlişkilerde Yaşantılar Envanteri-II ölçeğiyle belirlenmiştir. Annelerin duyarlılık davranışları yarı yapılandırılmış bir ortamda oyun hamurları yardımıyla 3-5 yaş çocuklarla annelerinin etkileşimleri dahilinde incelenmiştir. Sonuç olarak anneannelerin büyük çocuklarıyla bağlanma ilişkisinden dolayı nesillerarası bir aktarımın olduğu ancak bunun anneannelerin ikincil bağlanmaya sahip küçük kızlarını kapsamadıkları görülmüştür. Annelerin duyarlılık davranışlarında ikincil bağlanmaya

\footnotetext{
* Öğr. Gör., İstanbul Esenyurt Üniversitesi Sağlık Hizmetleri Yüksekokulu Çocuk Gelişimi Program1, İstanbul/Türkiye, zeynepdenizseven@esenyurt.edu.tr, orcid.org/0000-0003-3900989X.

** Prof. Dr., Fatih Sultan Mehmet Vakıf Üniversitesi Eğitim Fakültesi Okul Öncesi Öğretmenliği Bölümü, İstanbul/Türkiye, serdalseven@gmail.com, orcid.org/0000-0003-3965-4725.

*** Dr., Milli Eğitim Bakanlığı, Mersin/Türkiye, feyza_ucar@gmail.com, orcid.org/0000-00017341-0420.
} 
sahip olanlarının daha olumlu oldukları görülmektedir. Araştırma sonuçları nesiller arası aktarım ve hiyerarşik bağlanma biçimi teorilerini desteklemektedir.

Anahtar Kelimeler: Bağlanma, çoklu bağlanma, anne duyarlılığı, nesillerarası aktarım.

\title{
An Examination of Attachment and Sensitivity Behaviors Through Intergenerational Transfer on 3-5 Years-Old Children
}

\begin{abstract}
The aim of this study is to examine the reflection of attachment and sensitivity behaviors on children aged 3-5 with intergenerational transmission. The research has a mixed pattern. The study included 2 grandmothers and two daughters, one of whom had secondary attachment, with children between the ages of 3-5. Thus, a total of 10 people from 3 generations participated in the study. Attachment status was determined using the Experiences in Close Relationship Inventory-II scale. The sensitivity behaviors of the mothers were examined in a semi-structured environment with the help of play dough, within the interaction of children between 3-5 years and their mothers. As a result, it was observed that there was an intergenerational transmission due to the attachment relationship of grandmothers with their older children, but this did not include the grandmothers' younger daughters with secondary attachment. It is seen that those who have secondary attachment in mothers' sensitivity behaviors are more positive. The results of the research support the intergenerational transfer and hierarchical attachment style theories.
\end{abstract}

Keywords: Attachment, multiple attachment, mother sensitivity, intergenerational transmission. 


\section{Giriş}

Aile, bağlar vasıtasıyla varlığını devam ettirir. Yapılan araştırmalar anne-çocuk bağı kadar annenin kendi annesiyle olan bağının da önemli olduğunu göstermiştir. Bağlanma biçiminin nesiller boyu aktarıldığını destekleyen çalışmalar bulunmaktadır. Nesiller arası aktarımları inceleyen araştırmaların anneden anneye aktarımı varsaydıkları görülmektedir. Birçok kültürde geniş aile tarihsel bir gerçekliktir. En az ebeveyn ve çocuklardan meydana gelen bir çekirdek aile ve diğer kişilerden meydana gelen geniş aile, ülkemizde 2014 Türkiye İstatistik Kurumu verilerine göre \%16,7 iken 2019 yılında \%15 olduğu belirtilmektedir. Bugünkü çekirdek ailelerin kökeni de çoğunlukla geniş aile modeline dayanmaktadır. Geniş aile yapısı içerisinde ilişkiler organik yapıdadır. Bebeğin ve çocuğun ihtiyaçlarının karşılanması konusunda anneye abla, yenge, hala, teyze gibi unsurların da yardımcı olduğu hatta sorumluluğun çoğunluğunu aldıkları görülmektedir. $\mathrm{Bu}$ durumla ilgili bağlanma teorisinde iki kavram ön plana çıkmaktadır: nesiller arası geçiş ve hiyerarşik bağlanma.

Nesiller arası aktarma yaklaşımına göre, bağlanma biçimleri nesiller boyunca kalıcı olma eğilimindedir. Van IJzerndoorn $(1995)^{1}$ bir meta analiz çalışmasıyla nesiller arası aktarımla ilgili yayınları incelemiştir. 18 ülkeden örneklemin bulunduğu çalışmada yetişkin bağlanma sınıflandırmasından AAI sınıflamasının bebeklikteki yabancının durumu sınıflaması tarafından yordanabildiği sonucuna varmıştır. Buna göre güvenli annenin bebeğinin yetişkin olduğunda güvenli olması kaçınmalı annenin bebeğinin de yetişkin olduğunda kaçınmalı olması beklenir ${ }^{2}$.

Benzer şekilde, üç kuşak boyunca bağlanma kaderini araştırmak için yapılan bir çalışmada, büyükannelerin bağlanma sınıflandırmalarının sadece yetişkin kızlarının değil, aynı zamanda kızlarının çocuklarının bağlanma sınıflarına karşılık gelme eğiliminde olduğunu ortaya koymuştur ${ }^{3}$. Nesiller arası bağlanma iletiminin nasıl ve neden gerçekleştiği araştırmacılar için çok önemli bir sorudur. Aynı zamanda cevabı ebeveynlik için önemli etkileri olan bir sorudur. Annenin annelik becerisi anne duyarlılığı kavramı ile karşılık bulmaktadır. Annenin duyarlılığının en önemli göstergesi çocuğun mesajlarını fark etmesi, zamanında uygun tepkiler verebilmesine bağlıdır.

1 M. H. van IJzendoorn - M. J., Bakermans-Kranenburg, "Intergenerational transmission of attachment: A move to the contextual level", Attachment and Psychopathology, 1997, p. 135-170.

2 D. J. Wallin, Attachment in Psychotherapy, The Guilford Press, 2007.

3 E. Hesse, "The adult attachment interview: Historical and current perspectives", Handbook of attachment: Theory, research, and clinical applications, eds. J. Cassidy - P. R. Shaver, The Guilford Press, 1999, p. 395-433. 
Güvenli ebeveynlerin geniş davranışsal ve duyuşsal bir repertuara sahip oldukları ve bebeklerinin sinyalleri karşısında daha donanımlı oldukları görülmüştür$^{2}$. Bu duyarlılık Ainsworth ve diğerlerinin belirttiği gibi güven açısından merkezi bir rol oynamaktadır. Benzer şekilde, birlikte güvensiz ebeveynlerin de bu repertuarda yoksunlukları olduğu tahmin edilmektedir ${ }^{4}$.

Bununla birlikte, araştırmalar aynı zamanda ebeveynin önceki bağlanma tarz1 algısının, bağlanmanın kendisinden daha önemli olduğunu göstermiştir. Bir annenin birincil bakıcısıyla kendi tarihsel ilişkisini nasıl değerlendirdiği, kendi çocuğunun bağlılığının gelişmesinde merkezi bir öneme sahiptir 5 . Diğer bir anlatımla bağlanma ilişkisi annenin çocukla ilişkisi ve annenin kendi annesiyle ilişkisi olmak üzere iki yönlü olarak görülmektedir.

Aile sosyal kurumlar içinde en istikrarlı olanıdır. Çocuklar için aile ilişkilerin nasıl gelişmesi gerektiğine dair hazır kalıp davranışlar ve tutarlı tasvirler sunar. Çocuklar büyüdüklerinde, ailelerinin yıllar boyunca gösterdiği ilişki yapılarını kullanacaklardır.

Bazı ailelerde aile içinde çocuğun sıklıkla etkileşimde bulunduğu ve stresli durumlarda veya ihtiyaç duyduğunda yanında olan birincil olan anne figürü dışında ikincil veya üçüncül figürler de bulunabilir. Çoklu bağlanma olarak da düşünülen bu durumu Bowlby bağlanmada hiyerarşi olarak adlandırmıştır ${ }^{6}$. Bağlanma figürleri birbirlerinin yerine geçmez ama çocuğun tercih durumu ortaya çıkabilir ${ }^{7}$.

Bowlby $(1988)^{8}$ çocukların bakıcılar ile ilişkilerini bağlanma figürleri hiyerarşisinde organize ettiklerini savunmaktadır. Hiyerarşi kavramı, literatürde tartışılsa bile, tüm bakıcıların çocuğun bağlanma ihtiyaçlarını karşılamada eşit

4 M. D. S. Ainsworth - M. C. Blehar - E. Waters - S. Wall, Patterns of Attachment: A Psychological Study of The Strange Situation, New York, 1978.

5 M. S. Ainsworth - J. Bowlby, "An ethological approach to personality development" American Psychologist, 46(4), 1991, p. 333-341; M. Main - J. Soloman, "Procedures for identifying infants as disorganized/ disoriented during the Ainsworth Strange Situation", Attachment in the preschool years, eds. M. T. Greenberg - D. Cicchetti - E. M. Cummings, Chicago, University of Chicago, 1990, p. 121-160.

6 L. J. Berlin - J. Cassidy - K. Appleyard, "The influence of early attachments on other relationships", Handbook of attachment: Theory, research, and clinical applications, eds. J. Cassidy - P. R. Shaver, The Guilford Press, 2008, p. 333-347.

7 D. Davies, "Child Development: A practitioner's guide", Statewide Agricultural Land Use Baseline, vol. 3, 2015; doi: 10.1017/CBO9781107415324.004.

8 J. Bowlby, A Secure Base:Parent-Child Attachment and Healthy Human Development, USA, Perseus Books Group, 1988, p. 118-125. 
derecede önemli bir rol oynamadığını, ancak bağlanma sisteminin etkinleştirildiği zamanlarda çocuğun bir bakıcı için diğerine göre iyi tanımlanmış tercihler geliştirdiği görüşü hakimdir. Bowlby (1988) bağlanma hiyerarşisinde en çok tercih edilen bakıcıyı "asıl" veya birincil bağlanma figürü olarak tanımlamıştır ve diğer bakıcılar "yardımcı" (ikincil, üçüncül vb.) bağlanma figürleri olarak adlandırmıştır'.

Geniş aile modelinde nesilden nesile aktarımda ilişkinin öğrenilme biçimleri çeşitlenmektedir ${ }^{1}$. Bununla birlikte ikincil ve diğer çoklu ilişkilerin geniş aile modelinde yaygın olduğu bilinmektedir. Günümüzde çekirdek ailelerin büyük bir çoğunluğunun geniş aileden geldiği düşünüldüğünde geniş ailedeki ilişki modellerinin çekirdek ailede de sürdürüldüğü görülmektedir ${ }^{10}$. Birincil bağlanmayla birlikte yardımcı bağlanma ilişkileri yaşamış annelerin çocuklarıyla ilişkileri hâlihazırda bilinmemektedir. Diğer taraftan Dünya'da ve ülkemizde geniş aile ve bağlanma çalışmalarının oldukça sınırlı olduğu görülmektedir ${ }^{11}$. Geniş aile yapısında çoklu bağlanmanın annelik becerisi yani anne duyarlılığına etkisiyle birlikte oluşacak sonuçları da henüz bilinmemektedir.

$\mathrm{Bu}$ araştırmada nesiller arası bağlanma aktarımının yönü ve geniş ailede büyümüş birincil ve ikincil bağlanma ilişkisi kurmuş annelerin çocuklarına karşı duyarlılık durumlarının araştırılması amaçlanmıştır.

\section{Yöntem}

\section{Araştırmanın Yöntemi}

Araştırma nitel ve nicel yöntemin birlikte kullanıldığı karma bir modelle yapılmıştır. Nitel araştırmalar çeşitli görüşme, gözlem ve döküman inceleme gibi nitel veri toplama tekniklerinin kullanıldığı, alg1 ve olayların doğal ortamında gerçeğe uygun ve bütünü kapsayacak bir biçimde ortaya konmasına yönelik nitel bir sürecin izlendiği türde araştırmalardır ${ }^{12}$. Bu nitel araştırmada, durum çalışmasının bir türü olan gömülü çoklu durum araştırması kullanılmıştır ${ }^{13}$. Nesiller

9 A. C. Seibert - K. A. Kerns, “Attachment figures in middle childhood”, International Journal of Behavioral Development, 2009.

10 Z. D. Seven, "Farklı Aile Tiplerinde Yaşayan Anne ve 30- 42 Aylık Çocuklarının Anne Duyarlılığı Bağlamında Etkileşimlerinin İncelenmesi”, (Yayımlanmamış Yüksek Lisans Tezi), Okan Üniversitesi Sağlık Bilimleri Enstitüsü, İstanbul, 2017.

11 S. Seven - H. G. Ogelman, "Attachment Stability in Children Aged 6 to 9 Years in Extended and Nuclear Families", Early Education \& Development, 23(5), 2012, p. 766-780.

12 A. Yıldırım - H. Şimşek, Sosyal bilimlerde nitel araştırma yöntemleri, Ankara, Seçkin, 2000.

13 R. K. Yin, Case Study Research, Design and Methods, 3rd ed., vol. 5, London, SAGE Publications, 2003. 
arası aktarımla annelerin duyarlılıkları nitel araştırmalardan gömülü teori durum çalışması yöntem ile belirlenmiştir. Bağlanmanın nesiller arası kararlılı̆̆ının belirlenmesi amacıyla anneanne ve annelerin bağlanma puanları arasındaki ilişkiyi belirlemek için Pearson korelasyon katsayısı kullanılmıştır.

\section{Çalışma Grubu}

Çalışmaya katılan 3 nesil anneanne, anne ve torunlar ölçüt örnekleme temel alınarak belirlenmiştir. Ölçüt örnekleme amaçlı örnekleme yöntemi içerisinde yer alır. Belli nitelikteki kişi nesne, olay, durum bir araştırmada gözlem birimlerini oluşturabilir. Bu tür durumlarda örneklem için belirlenen kriteri karşılayan birimler örnekleme alınırlar. Var olan durumu en iyi açıklaması için bu araştırmada ölçüt örnekleme yöntem olarak seçilmiştir. Bu araştırmada ölçüt olarak her biri 3-5 yaşları arasında çocukları olan, geniş ailede büyümüş, biri ikincil bakıcısı olan iki kız kardeş ve geniş ailede büyümüş anneleri olarak belirlenmiştir. Çalışmaya bu kriterlere uygun iki aileden bireyler dahil edilmiştir. Bu kapsamda çalışma grubuna katılan bireyler aşağıda görüldüğü üzere Şekil 1.’de yer almaktadır.

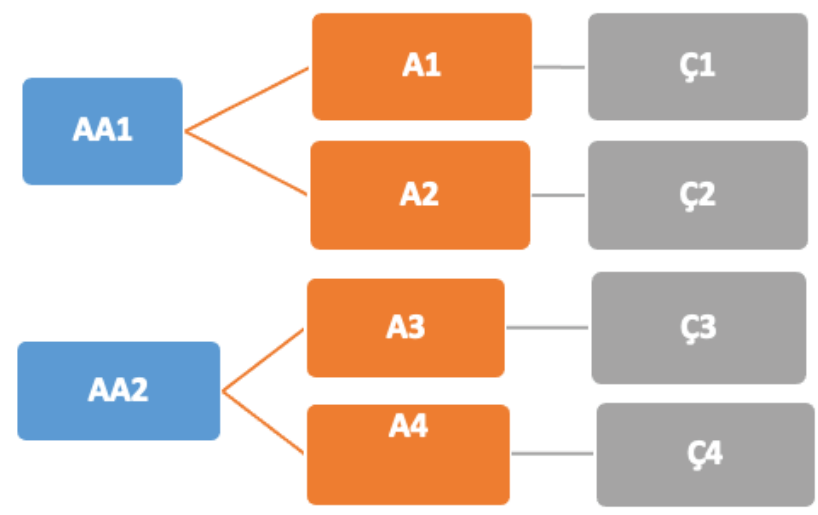

Şekil 1. Çalışma grubu

Araştırmaya 2 anneanne ve bunların 3-5 yaş çocuğa sahip ikişer kızları (4 anne) dahil edilmiştir. Böylece 3 nesilden toplam 10 kişi araştırmaya katılmıştır. Anneanneler ve anneler geniş ailede, çocukları da çekirdek ailede büyümüşlerdir. Anneanneler aynı yöreden olup evlendikten sonra İstanbul' da yaşamaya başlamışlardır. Geniş ailede A1, A2, A3, A4 anneleri tarafından bakı1mıştır. A1 ve A3 büyük çocuklar olduklarından daha çok anneleri tarafından bakılmışlardır. İkincil bağlanma figürleri olarak, A2 yengesi A4'e de babası tarafindan bakmıştır. Çocukların yaşları 42-60 ay arasındadır. Eğitim düzeyi olarak AA1 okuma yazma bilmemektedir. AA2 ise üniversite mezunudur. A1, A2, A3 ilköğretim mezunu- 
dur. A4 ise lise mezunudur. İki anneanne aynı yörede büyümüşlerdir. Anneannelerden AA1 74 yaşında, AA2 ise 55 yaşındadır. Bununla birlikte A1 45, A2 35, A3 33, A4 ise 28 yaşındadır. Ç1 ve Ç3 Erkek, Ç2 ve Ç4 ise kızdır.

\section{Veri Toplama Araçları}

$\mathrm{Bu}$ araştırmada anneanneler ile annelerin bağlanma ilişkilerini belirlemek amacıyla Yakın İlişkilerde Yaşantılar Envanteri-II anne-çocuk arasındaki etkileşimi belirlemek adına yarı yapılandırılmış oyun ve anne-çocuk gözlem formu kullanılmıştır.

\section{Anne- Çocuk Gözlem Formu}

Anne- Çocuk Gözlem Formu Gözlem boyunca anne ile çocuk arasındaki duyarlılı̆̆ ortaya çıkarak etkileşim davranışlarını belirlemek amacıyla ilgili alanyazın incelenerek oluşturulmuştur. Bu kapsamda anne duyarlılığına yön veren duyarlılık döngüsünün oluşumu ile ilgili gözlem davranış listesi hazırlanmıştır ${ }^{14}$. Oluşturulan gözlenecek davranış listesi 5 alan uzmanına gönderilmiştir. Uzmanlardan görüşlerine daire geri dönüşleri alındıktan sonra düzenlemeler yap1larak forma en son hali verilmiştir.

\section{Yakın İlişkilerde Yaşantılar Envanteri-II:}

Fraley, Waller ve Brennan ${ }^{15}$ tarafından yetişkinlerin bağlanmalarının çeşitli boyutlarda değerlendirilmesi için geliştirilmiştir. Ölçek 36 maddeden oluşmaktadır. 18 madde bağlanmanın kaygı boyutunda; 18 madde de kaçınma boyunda bulunmaktadır. İlgili maddeler her iki boyut için ayrı ayrı toplanmakta ve katılımcılar için ayrıca kaygı ve kaçınma puanları elde edilmektedir. Yüksek puanlar anlam olarak bağlanmanın kaygı ve kaçınma boyutlarındaki artı\$̧1 göstermektedir. Sümer ve Güngör ${ }^{16}$ tarafından YİYE-II'nin Türkçe dilinde geçerlik ve güvenirlik çalışmaları yapılmıştır. Bu çalışmanın sonucuna göre kaçınma ve kaygı boyutları yüksek düzeyde iç tutarlığa sahiptir. Diğer taraftan

14 F. Juffer - M. Bakermans-Kranenburg - M. H. van Ijzendoorn, "Methods of the video- feedback programs to promote positive parenting alone, with sensitive discipline, and with representational attachment discussions", Promoting Positive Parenting An Attachment-Based Intervention, eds. F. Juffer - M. Bakermans-Kranenburg - M. H. van Ijzendoorn, 2008, p. 11-21.

15 R. C. Fraley - N. G. Waller - K. A. Brennan, "An item response theory analysis of self-report measures of adult attachment”, Journal of Personality and Social Psychology, 78(2), 2000, p. $350-365$.

16 N. Sümer - D. Güngör, "Yetişkin Bağlanma Stilleri Ölçeklerinin Türk Örneklemi Üzerinde Psikometrik Değerlendirmesi ve Kültürlerarası Bir Karşılaştırma”, Türk Psikoloji Dergisi, 14(43), 1999, s. 71-106. 
Cronbach alfa katsayıları kaçınma için .90 ve kaygı için .86 olarak bulunmuştur. Test-tekrar test güvenirliği envanter için kaygı boyutunda .82, kaçınma boyutu için ise .81 olarak belirlenmiştir.

\section{Verilerin Toplanması}

Gözleme dayalı veriler anne çocuk çiftlerinin 10'ar dakikalık oyun etkinliklerinin, kamera kayıtları alınarak toplanmıştır. Anne çocuk bilgi formu ise görüşme tekniği ile oyun etkinlinden hemen sonra araştırmacı tarafından doldurulmuştur.

Gözlem doğal ortamda yapılandırılmış bir ortamda gerçekleşmiştir. Oyun etkinliği çalışmaya dahil olan bütün anne- çocuk çiftleri için benzer nitelikte 4 renk aynı özellikteki oyun hamuru kullanılarak yapılmıştır. Uygulama süresi 10 dakikadır. Oyun hamuru oyunlarında oyun kalıbı kullanılmamıştır. Uygulama anne-çocuk çiftinin doğal ortamı olan evlerinde yapılmıştır. Annenin ve çocuğun rahat hissetmeleri esas alınmıştır. Kamera araştırmacı tarafından çocuğun dikkatini çekmeyecek buna karşılık anne-çocuk davranışlarını açık bir şekilde kayıt altına alabilecek bir konuma yerleştirilmiştir. Gözlem süresince araştırmacı da aynı ortamda bulunmuştur. Uygulamaya hiçbir şekilde müdahale etmemiştir. Oyun uygulamaları Şubat 2021'de yapılmıştır. Uygulama öncesi ailelerden gerekli izinler ve kurumlardan etik kurul izni alınmıştır. Çalışmaya katılan anneanne ve annelere Yakın İlişkilerde Yaşantılar Envanteri-II uygulanmıştır.

\section{Verilerin Analizi}

Bu araştırmada veri analiz yöntemi olarak betimsel-yorumsal analiz kullanılmıştır. $\mathrm{Bu}$ analiz yönteminde veriler indirgenerek belli bir sıra oluşturulur, veriler seçilir ve nihayetinde yorum yapılır. Bu analiz türünde betimsel anlatımlar üzerine uygun yorumlara yer veriliir ${ }^{17}$. Bu araştırmada veriler incelenmiş, kategoriler oluşturularak tablolaştırılmış ve bulgular yazılarak sonuçlar yorumlanmıştır. Gözlem ile elde edilen video kayıtları 2 bağımısz kodlayıcı tarafından kodlanarak veriler oluşturulmuştur.

Ek olarak bu araştırma duyarlılık döngüsü ve göz kontağ 1 analizinde videografi (video etkileşim analizi) ve mikro- kod zaman serisi analiz yöntemleri kullanılmıştır. Mikro-kod analiz yönteminde gözlemler kısa zaman dilimleri dahilinde frekanslara ayrılarak incelenmektedir ${ }^{18}$. Bu çalışmada, Anne ve çocukların 10 dakikalık standart oyun süreçleri kısa zaman dilimlerine ayrıla-

17 D. Ekiz, Bilimsel Araştırma Yöntemleri, Lisans Yayıncılık, 2007.

180 C. Leclère - S. Viaux - M. Avril - C. Achard - M. Chetouani - S. Missonnier - D. Cohen, "Why synchrony matters during mother-child interactions: a systematic review", PLoS One, 9(12):e113571, 2014. 
rak incelenmiştir. Bu zaman serilerinde çocukların başlattıkları döngüler ve anne-çocuk arasındaki senkronizasyonu belirleyen işaretlerden biri olan göz kontakları belirlenmiştir.

\section{Bulgular}

\section{Bağlanma}

Anneannelerin bağlanma puanları ile iki kızlarının bağlanma puanları arasında ilişki Pearson Korelasyon katsayısı kullanılarak analiz edilmiştir. Analiz sonuçları aşağıda açıklanmıştır.

Tablo 1. Çalışmaya Katılan Birinci Anneannenin (AA1) Bağlanma Puanları ile Kızlarının Puanları Arasındaki Pearson Korelasyon Katsayıları

\begin{tabular}{llll}
\hline & $\boldsymbol{A A 1}$ & $\boldsymbol{A 2}$ & $\boldsymbol{A 1}$ \\
\hline $\boldsymbol{A A 1}$ & 1 &, 203 &, $477^{* *}$ \\
\hline $\boldsymbol{A} \boldsymbol{2}$ &, 203 & 1 &, 102 \\
\hline $\boldsymbol{A 1}$ &, $477^{* *}$ &, 102 & 1 \\
\hline
\end{tabular}

Çalışmaya katılan 1. gruptaki anneannenin bağlanma puanı ile iki kızının bağlanma puanlarının tutarlılığı Pearson Korelasyon katsayısı ile analiz edilmiştir. Anneannenin bağlanma puanının ilk çocuğuyla anlamlı pozitif bir ilişkiye ( $\mathrm{r}$ $=, 477, \mathrm{p}<.01)$ sahip olduğu bulunmuştur. Ancak anneannelerin bağlanma puanları ile ikinci çocuklarının puanları arasında anlamlı bir ilişki $(r=, 203, p>0,05)$ olmadığı saptanmıştır.

Tablo 2. Çalışmaya Katılan İkinci Anneannenin (AA2) Bağlanma Puanları ile Kızlarının Puanları Arasındaki Pearson Korelasyon Katsayıları

\begin{tabular}{llll}
\hline & AA2 & A4 & A3 \\
\hline $\mathbf{A A 2}$ & 1 &, 245 &, $363^{*}$ \\
\hline $\mathbf{A 4}$ &, 245 & 1 &, $639^{* *}$ \\
\hline $\mathbf{A 3}$ &, $363^{*}$ & $639^{* *}$ & 1 \\
\hline
\end{tabular}

2. gruptaki anneannenin bağlanma puanı ile iki kızının bağlanma puanlarının tutarlılı̆̆ 1 Pearson Korelasyon katsayısı ile analiz edilmiştir. Anneannenin bağlanma puanının ilk çocuğuyla anlamlı pozitif bir ilişkiye $(r=, 363, p<.05)$ sahip olduğu bulunmuştur. Ancak anneannelerin bağlanma puanları ile ikinci çocuk- 
larının puanları arasında anlamlı bir ilişki $(\mathrm{r}=, 245, \mathrm{p}>0,05)$ bulunmamıştır. $\mathrm{Bu}$ verilere göre anneannelerin birincil bağlanmaya sahip büyük kıları ile bağlanma ilişkisi olduğu ancak ikinci bağlanmaya sahip küçük kızları ile ilişki olmadığı anlaşılmaktadır.

\section{Anne Duyarlılığı}

Annelerin çocuklarıyla etkileşimleri sonucunda oluşan duyarlılık döngülerinin niteliği aşağıda açıklanmıştır.

Tablo 3. Çocuk ve Anne Etkileşimlerine Ait Duyarlılık Döngüleri

\begin{tabular}{|l|l|l|l|l|}
\hline Ç1 Sinyal & \multicolumn{2}{|l|}{ A1 Tepki } & \multicolumn{2}{l|}{ Ç1 Tepki } \\
\hline Sözsüz & Olumsuz & Sözlü & Olumsuz & Sözsüz (Tepkisiz) \\
\hline Ç2 Sinyal & \multicolumn{2}{|l|}{ A2 Tepki } & \multicolumn{1}{l|}{ Ç2 Tepki } \\
\hline Sözlü & Olumlu & Sözlü & Olumlu & Sözsüz \\
\hline Ç3 Sinyal & A3 Tepki & \multicolumn{1}{l|}{ Ç3 Tepki } \\
\hline Sözlü & Olumsuz & Sözsüz & Olumsuz & Sözsüz \\
\hline Ç4 Sinyal & A4 Tepki & \multicolumn{2}{l|}{} \\
\hline Sözlü Tepki & Olumlu & Sözlü & Olumlu & Sözlü \\
\hline
\end{tabular}

Ç1-A1 arasındaki duyarl111k döngüsü incelendiğinde Ç1'in daha çok sözsüz mesajlar gönderdiği A1'in bu mesajlara olumsuz tepkiler verdiği ve döngünün sonunda Ç1'in olumsuz tepkiler gösterdiği görülmektedir. Bu yönüyle annenin duyarlılık göstermediği anlaşılmaktadır.

Ç2-A2 arasındaki duyarlılık döngüsü incelendiğinde Ç2'in daha çok sözlü mesajlar gönderdiği A2'in bu mesajlara olumlu tepkiler verdiği ve döngünün sonunda Ç2'nin olumlu tepkiler gösterdiği görülmektedir. Bu yönüyle annenin duyarlı olduğu anlaşılmaktadır.

Ç3-A3 arasındaki duyarlılık döngüsü incelendiğinde Ç3'ün daha çok sözlü mesajlar gönderdiği A3'ün bu mesajlara sözsüz olumsuz tepkiler verdiği ve döngünün sonunda Ç3’ün olumsuz sözsüz tepkiler gösterdiği görülmektedir. Bu yönüyle annenin duyarlılık göstermediği belirlenmiştir.

Ç4-A4 arasındaki duyarlılık döngüsü incelendiğinde Ç4'in daha çok sözlü mesajlar gönderdiği A4'ün bu mesajlara olumlu sözlü tepkiler verdiği ve döngünün sonunda Ç4'ün olumlu sözlü tepkiler gösterdiği görülmektedir. $\mathrm{Bu}$ yönüyle annenin duyarlı olduğu belirlenmiştir. 


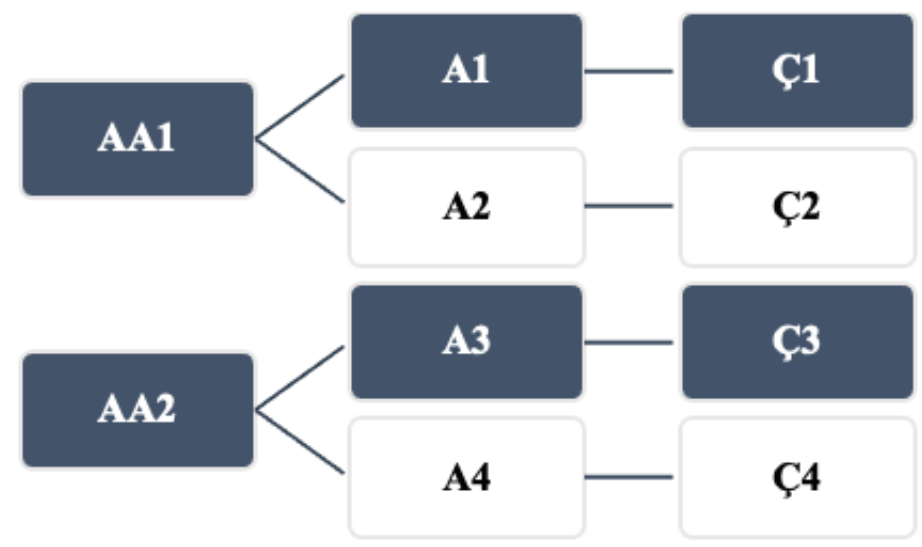

Şekil 2. Anne-anne, Anne ve Çocuk Arası Bağlanma ve Duyarlılık İlişkisi

Şekil 2'de bulunan AA1, çalışma grubuna katılan birinci anneannedir. AA1'in A1 ve A2 kodlu kızları bulunmaktadır. A1'in Ç1, A2'nin Ç2 çocuğudur. AA2, çalışma grubuna katılan ikinci anneannedir. AA2'nin A3 ve A4 kodlu kızları bulunmaktadır. A3'ün Ç3, A4'ün Ç4 kodlu kızı bulunmaktadır. A1 ve A3 büyük çocuklar olduklarından daha çok anneleri tarafından bakılmışlardır. İkincil bağlanma figürleri olarak, A2 yengesi A4'e de babası tarafından bakmıştır.

Tablo 4. Anne ile Çocuk arasında gerçekleşen Göz Kontağı etkileşimi

\begin{tabular}{|l|l|l|l|l|}
\hline & \multicolumn{2}{|l|}{ Başarılı } & \multicolumn{2}{l|}{ Başarısız } \\
\hline & $\begin{array}{l}\text { Çocuk } \\
\text { tarafindan } \\
\text { başlatılan }\end{array}$ & $\begin{array}{l}\text { Anne } \\
\text { tarafindan } \\
\text { başlatılan }\end{array}$ & $\begin{array}{l}\text { Çocuk } \\
\text { tarafindan } \\
\text { başlatılan }\end{array}$ & $\begin{array}{l}\text { Anne } \\
\text { tarafindan } \\
\text { başlatılan }\end{array}$ \\
\hline A1-Ç1 & 2 & 14 & 13 & 15 \\
\hline A2-Ç2 & 4 & 1 & 0 & 5 \\
\hline A3-Ç3 & 1 & 3 & 8 & 15 \\
\hline A4-Ç4 & 1 & 2 & 1 & 18 \\
\hline
\end{tabular}

Ç1'in göz kontağı arayışlarının A1 tarafindan neredeyse karşı1ıksız kaldığ1 görülmüştür. AA1'in kızı A2'nin çocuğuyla etkileşiminde duyarlık döngüsünde olduğu gibi göz kontağında da başarılı olduğu bulunmuştur. A3- Ç3 etkileşiminde çocuğun göz kontağı arayışları anne tarafından neredeyse hiç karşılık bulmamıştır. A3 sık göz kontağı girişimlerinin çocuklar üzerinde olumsuz etki bıraktığı görülmüştür. A4-Ç4 göz kontağı ilişkisinin karşılıklı olarak büyük oranda başarısız olduğu görülmüştür. 


\section{Tartışma, Sonuç ve Öneriler}

Bu çalışmada, nesiller arası bağlanma aktarımının yönü ve geniş ailede büyümüş birincil ve ikincil bağlanma ilişkisi kurmuş annelerin çocuklarına karş1 duyarlılık durumlarının araştırılması amaçlanmıştır. Araştırma sonuçları, ilgili literatür ışığında tartışılmıştır.

Araştırmada her iki anneannenin de kızlarından büyük olanı ile bağlanma ilişkisi pozitif yönde anlamlı olarak bulunmuştur. Bu ilişki yönünün pozitif olmas1, güvenli bağlanan annenin çocuğunun da benzer şekilde güvenli bağlanma, güvensiz bağlanan annenin çocuğunun kuracağı bağlanmanın güvensiz bağlanma göstermesi olarak açıklanmaktadır. Bu çalışmada her iki grupta anneannelerin güvensiz olmaları ilk çocuklarının da güvensiz oldukları anlamına gelmektedir. Diğer bir anlatımla birincil bağlanma figürü ile bağlanma ilişkisinin tutarlı olduğu görülmüştür. Bağlanma kuramına göre bağlanma figürü olarak annelerin kendi bağlanma deneyimlerinin bir model olarak çocuklarına aktarıldığ 1 öne sürülmektedir. Bu sonuca benzer olarak literatürde annelerin erken çocukluk yıllarında ebeveynlik deneyimlerinin olumsuz olması, anneleri ile olan bağlanma örüntülerini ve ebeveynlik davranışlarını olumsuz etkilediği ile ilgili çalışmalar da mevcuttur $^{19}$. Zor bir çocukluk dönemi geçiren annelerin birincil bağlanma figürleri ile deneyimlerinden kaynaklanan dağınık zihinsel durumlarının; kendi çocuklarına karşı ilgisiz bir ebeveynlik sergilemelerine de yol açabildiği düşünülmektedir ${ }^{20}$. Buna paralel olarak yapılan bazı araştırmalarda da, anne ile kendi annesi ile arasında kurulan güvenli bağlanma, kendi çocuklarıyla da güvenli bağlanmasını kolaylaştırabilmektedir ${ }^{21}$. Şen ve Kavlak ${ }^{22}$ yaptıkları araştırmada anneannelerin çocukları ile güvenli bağ kurmalarının, kızları anne olduğunda bebekleriyle güvenli bir bağ geliştirmesinde rol oynadığı sonucuna ulaşmıştır. Araştırmanın sonucuna

19 M. Main - N. Kaplan - J. Cassidy, "Security in infancy, childhood, and adulthood: A move to the level of representation", Monographs of the Society for Research in Child Development, 50(1-2), 1985, p. 66-104; L. Serbin - J. Karp, "Intergenerational studies of parenting and the transfer of risk from parent to child", Current Directions in Psychological Science, 12(4), 2003, p. 138-142.

20 L. Zajac - K. L. Raby - M. Dozier, "Attachment state of mind and childhood experiences of maltreatment as predictors of sensitive care from infancy through middle childhood: Results from a longitudinal study of parents involved with Child Protective Services”, Development and Psychopathology, 31(1), 2019, p. 113-125.

21 U. Iyengar - S. Kim - S. Martinez - P. Fonagy - L. Strathearn, "Unresolved trauma in mothers: intergenerational effects and the role of reorganization", Frontiers in Psychology, 5, 2014.

22 S. Şen - O. Kavlak, "Transgenerational attachment in Manisa, Turkey”, Contemporary Nurse, 41(1), 2012, p. 126-132. 
benzer olarak güvenli bağlanan annelerin daha güçlü annelik bağlarının olduğu ve kızlarının da aynı bağlanma örüntüsünü geliștirdikleri belirlenmiştir.

Araştırmaya katılan anneannelerin her ikisinin de büyük çocuğunun çocuğu ile olan duyarlılık döngüsünü başlatma girişimi neredeyse hiç olmamıştır. Annelerin duyarlı1ık döngüsünün olumsuz olduğu, çocuğun fazlaca göz kontağı arayışlarının anne tarafindan neredeyse karşılıksız kaldığı belirlenmiştir. Nesiller arası aktarılan ebeveynlik, kişilerin geçmişinden gelmekte ve çocukları ile yaşamlarında olumlu ya da olumsuz davranışları da beraberinde getirmektedir. Bir anne, annesiyle bağında bir kopukluk yaşadığında ya da kalıtsal bir travma söz konusu olduğunda bu durum bebeği ile arasında oluşan bağı olumsuz yönde etkileyebi$\operatorname{lir}^{23}$. Bu bağın oluşabilmesinde anne ile çocuk arasında sağlıklı ilişkinin kurulmas1 oldukça önemlidir. İyi bir anne çocuk ilişkisinde, annenin çocuğu ile iletişim kurarken sözel ve sözel olmayan iletişim yollarından faydalanması, çocuğunu koşulsuz kabul etmesi, çocuktan gelen sinyalleri doğru okuması beklenmektedir. Winnicott ${ }^{24}$, annenin gözlerine bakarak çocuğun kendisini gördüğünü belirtmektedir. Uçar-Çabuk ${ }^{25}$ tarafından yapılan araştırmada, çocukları ile konuşurken ben dilini kullanan, göz teması kuran, çocuğun hizasına eğilerek net ifadeler kullanan ebeveynlerin çocukları ile sağlıklı ilişki kurdukları sonucuna ulaşılmıştır. Lohrasbe ve Ogden'e göre ebeveynin çocuk ile kurduğu göz teması, yumuşak bir ses tonu, çocuğun hizasına eğilme ve çocuğa dokunma, uyarıyı içeren herhangi bir sözel ifadeden çok daha etkilidir ${ }^{26}$. Bu bağlamda yapılan çalışmada güvensiz bağlanmaya sahip anneannenin çocuğunun, çocuğu ile duyarlılık döngüsünün olumsuz olması anneannenin güvensiz bağlanmasına ve bu durumun çocuğuna ve onun da çocuğu ile kurduğu bağlanmaya yansıması ile açıklanabilir.

Diğer taraftan, Seven (2017) ${ }^{11}$ tarafından yapılan araştırmada geniş aile biçiminden gelen ve çekirdek aile kuran annelerin çocuklarıyla duyarlı bir ilişki geliştirmelerinde geleneksel bazı uygulamaların sınırlandırıcı etki oluşturduğu

23 M. Wolynn, It didn't start with you: How inherited family trauma shapes who we are and how to end the cycle, 2016, p. 14-61.

24 D. W. Winnicott, "Mirror-role of mother and family in child development", Playing and reality, London, Tavistock Publications, 1971, p. 86-94.

25 F. Uçar Çabuk, "Ebeveyn çocuk iletişimi eğitim programının ebeveyn çocuk ilişkisine ve iletişimine etkisinin incelenmesi”, (Yayımlanmamış Doktora Tezi), Gazi Üniversitesi, Eğitim Bilimleri Enstitüsü, Ankara, 2017.

26 R. Lohrasbe - P. Ogden, "Somatic resources: Sensorimotor psychotherapy approach to stabilising arousal in child and family treatment", Australian and New Zealand Journal of Family Therapy, 38(4), 2017, p. 573-581. 
bulunmuştur. İlhan Ildız \& Seven ${ }^{27}$ tarafindan yapılan ve bu araştırmayı destekleyen bir başka çalışmada da özellikle anne, baba ve çocuk arasındaki etkileşimi olumsuz etkileyen sevgiyi ve duygusal aktarımı sınırlandıran Anadolu'da özellikle geniş aile modelinde yer almış bazı geleneksel uygulamaların olduğu ve bu uygulamaların nesilden nesile bir eksiklik olarak aktarıldığı tartışılmıştır.

Araştırmaya katılan anneannelerin her ikisinin de küçük çocuğunun çocuğu ile olan etkileşiminde duyarlılık döngüsünün olumlu olduğu, göz kontağını başarılı kurdukları sonucuna ulaşılmıştır. Bowlby'nin hiyerarşi kavramı, tüm bakıcıların çocuğun bağlanma ihtiyaçlarını karşılamada eşit derecede önemli bir rol oynamadığını, ancak bağlanma sisteminin etkinleştirildiği zamanlarda çocuğun bir bakıcı için diğerine göre iyi tanımlanmış tercihler geliştirdiği görüşünü savunmaktadır. Bowlby bağlanma hiyerarşisinde en çok tercih edilen bakıcıyı "asıl" veya birincil bağlanma figürü olarak tanımlamıştır ve diğer bakıcılar "yardımcı" (ikincil, üçüncül vb.) bağlanma figürleri olarak adlandırmıştır ${ }^{28}$. Bu bağlamda yapılan bu çalışmada da anneannelerin ikinci çocuklarının anne dışında bakımlarını üstlenen ve ihtiyaçlarını karşılayan kişi olduğu ve bağlanma figürünün anne olmadığı bilinmektedir. Anneannelerin ikinci çocuklarının bağlanma figürünün değişmesinin, çocuklarıyla olan bağlanmalarını ve duyarlılık döngülerini olumlu etkilemesi ile açıklanabilir. İstikbal $(2020)^{29}$, nesiller arası yaptığı çalışmada erken dönem bağlanma deneyimlerinin belirli kalıplar halinde iletilmediğini, bunun yerine daha örtük bir şekilde bazı kapasitelerin gelişiminde yarattıkları aksaklıklar nedeniyle sonraki nesilleri etkilediklerini savunmaktadır. Çalışmasında annelerin anneleri ile olan ilişkilerinde deneyimledikleri kopuklukta özellikle fiziksel temasın yokluğuna dair bulguların dikkat çektiğini ve güvenli bağlanmanın en önemli koşullarından birinin duygusal senkronizasyon ve fiziksel dokunuş olduğunu ifade etmektedir. Motattaianu ${ }^{30}$ (2015)'e göre duygusal ve fiziksel bağlantı, çocuğu sakinleştirebilmek ve kendisini güvende hissettirebilmek için hayati bileşenlerdir. Duygulanım düzenleme örüntüleri ile ilişkili olarak bağlanmanın,

27 G. İlhan Ildız - S. Seven, "30 ile 45 yaşları arasındaki yetişkinlerin sevgiyi alma ve aktarma biçimleri üzerine nitel bir çalışma”, ULEAD 2018 Annual Congress, 21, 2018.

28 K. A. Kerns - M. M. Abraham - A. Schlegelmilch - T. A. Morgan, "Mother-child attachment in later middle childhood: Assessment approaches and associations with mood and emotion regulation", Attachment \& Human Development, 9(1), 2007, p. 33-53.

29 E. İstikbal, "Anne Çocuk İlişkilerinin Nesiller Arası Aktarımının Annelerin Anlatıları Üzerinden Niteliksel Yöntemle Araştırılması”, (Yayımlanmamış Yüksek Lisans Tezi), Maltepe Üniversitesi Lisansüstü Eğitim Enstitüsü, İstanbul, 2020.

30 I. R. Motataianu, "Parent-child Connection - Emotional synchronization and playing; A possible model to combat the child's unsafe attachment", Procedia - Social and Behavioral Sciences, 180, 2015, p. 1178-1183. 
başka bağlamlarda da devam ettiği bilinmektedir ${ }^{31}$. Siegel ve Hartzell ${ }^{31}$ (2003)'e göre, anne genellikle bebeğin birincil bağlanma figürü olarak görülmekte ancak kimi zaman bebeğin bakımıyla ve ihtiyaçlarıyla ilgilenen sevgi dolu bir bakıcı da bu rolü üstlenebilmektedir. Yapılan bu çalışmada anneannelerin büyük çocuklarıyla ve onların da çocuklarıyla olan bağlanma yönlerinin ve duyarlılık döngülerinin benzer olarak nesiller arası aktarımının sağlandığ1 görülürken, diğer çocuklarının çocuklarıyla kurdukları bağlanma yönünde ve duyarlılık döngüsünde farklılaşma olmaktadır. Bu durum, geniş ailede çocuğun bakımında anne dışında bireylerin de görev alması ile bağlanmanın ve duyarlılı̆̆ın aktarımının bu kişilere bağlı olarak aktarılması ile açıklanabilir.

Yurt içi ve yurt dışı yapılan çalışmalarda nesiller arası bağlanma ve duyarlılık ile ilgili çalışmaların az olması nedeniyle bu çalışmanın literatüre olumlu katkı sunacağ düşünülmektedir. Geniş aile ile yapılacak bağlanma ve duyarlılık çalışmalarında salt anne- çocuk ilişkisinin yanıltıcı olabileceği düşünülmektedir. Bu çalışmada iki nesil ile gözlemler ve görüşmeler mevcuttur. Yapılacak çalışmalarda üç nesile de odaklanılması ve babaların ve diğer aile üyelerinin araştırmaya dahil edilmesi önerilebilir. Araştırmaya katılan annelerin sosyo-ekonomik düzeyleri benzer özelliktedir. Farklı sosyo-ekonomik özelliklere sahip katılımc1lar ve farklı ölçme araçlarıyla ilgili araştırmalar yapılması önerilebilir. Geniş aileden çekirdek aileye geçişte bağlanma ve duyarlılık davranışların aktarımı ile ilgili ülkemizde daha fazla araştırmaya ihtiyaç duyulmaktadır. Nesiller arası geçişin anlaşılması için geniş örneklemde nicel çalışmalarla birlikte aktarılan davranış kalıplarının türlerinin belirlenmesi için de nitel araştırmalara ihtiyaç olduğu düşünülmektedir. help you raise children who thrive, New York, Jeremy P. Tarcher/Putnam, 2003, p. 2-80. 


\section{Kaynakça}

Ainsworth, M. D. S. - Blehar, M. C. - Waters, E. - Wall, S., Patterns of Attachment: A Psychological Study of The Strange Situation, New York, 1978.

Ainsworth, M. S. - Bowlby, J., "An ethological approach to personality development” American Psychologist, 46(4), 1991.

Berlin, L. J. - Cassidy, J. - Appleyard, K., "The influence of early attachments on other relationships", Handbook of attachment: Theory, research, and clinical applications, eds. J. Cassidy - P. R. Shaver, The Guilford Press, 2008.

Bowlby, J., A Secure Base:Parent-Child Attachment and Healthy Human Development, USA, Perseus Books Group, 1988.

Davies, D., "Child Development: A practitioner's guide", Statewide Agricultural Land Use Baseline, vol. 3, 2015; doi: 10.1017/CBO9781107415324.004.

Ekiz, D., Bilimsel Araştırma Yöntemleri, Lisans Yayıncılık, 2007.

Fraley, R. C. - Waller, N. G. - Brennan, K. A., "An item response theory analysis of self-report measures of adult attachment", Journal of Personality and Social Psychology, 78(2), 2000.

Hesse, E., "The adult attachment interview: Historical and current perspectives", Handbook of attachment: Theory, research, and clinical applications, eds. J. Cassidy - P. R. Shaver, The Guilford Press, 1999.

Iyengar, U. - Kim, S. - Martinez, S. - Fonagy, P. - Strathearn, L., "Unresolved trauma in mothers: intergenerational effects and the role of reorganization", Frontiers in Psychology, 5, 2014.

İlhan Ildız, G. - Seven, S., "30 ile 45 yaşları arasındaki yetişkinlerin sevgiyi alma ve aktarma biçimleri üzerine nitel bir çalışma”, ULEAD 2018 Annual Congress, 21, 2018.

İstikbal, E., "Anne Çocuk İlişkilerinin Nesiller Arası Aktarımının Annelerin Anlatıları Üzerinden Niteliksel Yöntemle Araştırılması", (Yayımlanmamış Yüksek Lisans Tezi), Maltepe Üniversitesi Lisansüstü Eğitim Enstitüsü, İstanbul, 2020 .

Juffer, F. - Bakermans-Kranenburg, M. - van Ijzendoorn, M. H., "Methods of the video- feedback programs to promote positive parenting alone, with sensitive discipline, and with representational attachment discussions", Promoting Positive Parenting An Attachment-Based Intervention, eds. F. Juffer - M. Bakermans-Kranenburg - M. H. van Ijzendoorn, 2008. 
Kerns, K. A. - Abraham, M. M. - Schlegelmilch, A. - Morgan, T. A., "Mother-child attachment in later middle childhood: Assessment approaches and associations with mood and emotion regulation", Attachment \& Human Development, 9(1), 2007.

Leclère C. - Viaux S. - Avril M. - Achard C. - Chetouani M. - Missonnier S.- Cohen D., "Why synchrony matters during mother-child interactions: a systematic review", PLoS One, 9(12):e113571, 2014.

Lohrasbe, R. - Ogden, P., "Somatic resources: Sensorimotor psychotherapy approach to stabilising arousal in child and family treatment", Australian and New Zealand Journal of Family Therapy, 38(4), 2017.

Main, M. - Kaplan, N. - Cassidy, J., "Security in infancy, childhood, and adulthood: A move to the level of representation", Monographs of the Society for Research in Child Development, 50(1-2), 1985.

Main, M. - Soloman, J., "Procedures for identifying infants as disorganized/ disoriented during the Ainsworth Strange Situation", Attachment in the preschool years, eds. M. T. Greenberg - D. Cicchetti - E. M. Cummings, Chicago, University of Chicago, 1990.

Motataianu, I. R., "Parent-child Connection - Emotional synchronization and playing; A possible model to combat the child's unsafe attachment", Procedia - Social and Behavioral Sciences, 180, 2015.

Seibert, A. C. - Kerns, K. A., "Attachment figures in middle childhood", International Journal of Behavioral Development, 2009.

Serbin, L. - Karp, J., "Intergenerational studies of parenting and the transfer of risk from parent to child", Current Directions in Psychological Science, 12(4), 2003.

Seven, S. - Ogelman, H. G., "Attachment Stability in Children Aged 6 to 9 Years in Extended and Nuclear Families", Early Education \& Development, 23(5), 2012.

Seven, Z. D., "Farklı Aile Tiplerinde Yaşayan Anne ve 30- 42 Aylık Çocuklarının Anne Duyarlılığı Bağlamında Etkileşimlerinin İncelenmesi”, (Yayımlanmamış Yüksek Lisans Tezi), Okan Üniversitesi Sağl1k Bilimleri Enstitüsü, İstanbul, 2017.

Siegel, D. J. - Hartzell, M., Parenting from the inside out: How a deeper self-understanding can help you raise children who thrive, New York, Jeremy P. Tarcher/Putnam, 2003. 
Sümer, N. - Güngör, D., "Yetişkin Bağlanma Stilleri Ölçeklerinin Türk Örneklemi Üzerinde Psikometrik Değerlendirmesi ve Kültürlerarası Bir Karşılaştırma”, Türk Psikoloji Dergisi, 14(43), 1999.

Şen, S. - Kavlak, O., "Transgenerational attachment in Manisa Turkey", Contemporary Nurse, 41(1), 2012.

Uçar Çabuk, F., "Ebeveyn çocuk iletişimi eğitim programının ebeveyn çocuk ilişkisine ve iletişimine etkisinin incelenmesi”, (Yayımlanmamış Doktora Tezi), Gazi Üniversitesi, Eğitim Bilimleri Enstitüsü, Ankara, 2017.

Van IJzendoorn, M. H. - Bakermans-kranenburg, M. J., "Intergenerational transmission of attachment: A move to the contextual level", Attachment and Psychopathology, 1997.

Wallin, D. J., Attachment in Psychotherapy, The Guilford Press, 2007.

Winnicott, D. W., "Mirror-role of mother and family in child development", Playing and reality, London, Tavistock Publications, 1971.

Wolynn, M., It didn't start with you: How inherited family trauma shapes who we are and how to end the cycle, 2016.

Yıldırım, A. - Şimşek, H., Sosyal bilimlerde nitel araştırma yöntemleri, Ankara, Seçkin, 2000.

Yin, R. K., Case Study Research, Design and Methods, 3rd ed., vol. 5, London, SAGE Publications, 2003.

Zajac, L. - Raby, K. L. - Dozier, M., “Attachment state of mind and childhood experiences of maltreatment as predictors of sensitive care from infancy through middle childhood: Results from a longitudinal study of parents involved with Child Protective Services", Development and Psychopathology, 31(1), 2019.

\section{Araştırmacıların Katkı Oranı}

Araştırmacıların her birisinin mevcut araştırmaya katkı oranı aşağıdaki gibidir.

Yazar 1: \%50 (Planlama ve uygulama)

Yazar 2: \%30 (Verilerin işlenmesi, bulgular ve tartışma)

Yazar 3: \%20 (Giriş)

\section{Çatışma Beyanı}

Araştırmada herhangi bir çıkar çatışması bulunmamaktadır. 